Linguagem em (Dis)curso - LemD, v. 8, n. 3, p. 417-437, set./dez. 2008

\title{
OS MEDIADORES DAS PRÁTICAS DE LETRAMENTO DE PROFESSORES EM FORMAÇÃO INICIAL
}

Ana Lúcia Guedes-Pinto*

\begin{abstract}
Resumo: Tomando como base a geração de dados proporcionada pela pesquisa "Formação do professor: processos de retextualização e práticas de letramento", focalizo o processo de apropriação da prática de leitura vivenciado pelos professores em formação inicial. Nas narrativas de memórias sobre suas experiências pessoais da infância, da juventude e da contemporaneidade do curso de Pedagogia, identificamos indícios de como esses sujeitos se inseriram nas práticas de letramento das quais se apropriaram ao longo de seus percursos. Nesse processo de inserção no mundo da escrita, conforme narrado pelos professores, emergem diversos mediadores de suas práticas leitoras. Tendo como referência teórico-metodológica do trabalho de campo a História Oral, os princípios da etnografia e assumindo a abordagem dos Estudos do Letramento e da História Cultural, procuro identificar esses diferentes mediadores e discutir seu papel no percurso de formação do profissional do ensino. Considerando, portanto, a memória de leituras narradas e o que elas nos trazem de conhecimento acerca dos variados personagens que co-protagonizaram suas histórias, busco apontar possibilidades de trabalho com relação à formação de professores.
\end{abstract}

Palavras-chave: letramento; leitura; formação de professores; memória; narrativa.

\section{INTRODUÇÃO: SOBRE O RECORTE DA PESQUISA}

Neste artigo tomo como foco de discussão o processo de apropriação da prática de leitura vivenciado pelos professores em

\footnotetext{
* Professora do Departamento de Ensino e Práticas Culturais da Faculdade de Educação da UNICAMP. Coordenadora do grupo de pesquisa AULA - Trabalho Docente na Formação Inicial. Doutora em Lingüística Aplicada. E-mail: <alguedes@mpc.com.br>.
} 


\section{8}

formação inicial. Por meio da análise de suas narrativas sobre a memória de suas experiências pessoais vividas no período da infância, da adolescência e também da contemporaneidade do curso de Pedagogia ${ }^{1}$, procurarei sistematizar algumas contribuições para o campo dos Estudos do Letramento acerca da constituição dos sujeitos leitores.

Nos dizeres dos professores encontramos diversos indícios que nos trazem informações sobre como esses sujeitos foram se inserindo nas práticas de letramento nas quais se integraram e de que se apropriaram ao longo de seu percurso pessoal e profissional. Em seus relatos sobre esse processo de imersão no mundo da escrita aparecem diversos tipos de mediadores, sujeitos individuais ou institucionais, que participam/participaram de suas histórias de leitores.

Tendo como referência teórico-metodológica para o trabalho de campo desenvolvido durante a pesquisa ${ }^{2}$ a perspectiva da História Oral, os princípios da etnografia e também assumindo o diálogo entre as abordagens dos Estudos do Letramento $^{3}$ (STREET, 1984, 2007; KLEIMAN, 1995) e da História Cultural, principalmente os trabalhos de Chartier (1990, 1998, 2001), neste texto procuro identificar diferentes mediadores do processo de apropriação da prática leitora e destacar seu papel e sua importância no percurso de formação do profissional do ensino. Considerando, portanto, a memória de leituras narradas e o que elas nos fornecem de conhecimento acerca dos variados personagens

\footnotetext{
${ }^{1}$ Trata-se do curso de graduação em Pedagogia dos períodos noturno e diurno e do curso Pefopex Programa Especial para Formação de Professores em Exercício da Faculdade de Educação da Unicamp.

2 Nos últimos quatro anos e meio (de 2003 a 2007) participei como pesquisadora principal do projeto temático coordenado pela professora Kleiman, financiado pela Fapesp, intitulado Formação do Professor: processos de retextualização e práticas de letramento (processo 2002/09775-0), coordenando uma das equipes de trabalho. Nossa linha de investigação, denominada Legibilidade e Leituras do Formador de Leitores, teve como foco recuperar as memórias de leitura dos professores em formação inicial.

${ }^{3}$ Kleiman (1995), ao examinar as concepções predominantes sobre o letramento que orientavam as pesquisas no Brasil na época da escrita de seu artigo, tece uma pequena introdução em que situa os Estudos do Letramento, a cunhagem do seu termo na língua portuguesa e sua influência nos estudos brasileiros que buscavam investigar o impacto social da escrita. Os estudiosos ingleses (principalmente o grupo de pesquisadores ligados a Street, 2007) têm denominado suas pesquisas atuais sobre o letramento como pertencentes à perspectiva dos "Novos Estudos do Letramento". Não adoto essa tradução direta para o português uma vez que a perspectiva dos Estudos do Letramento no Brasil é relativamente recente, como Kleiman (1995) explicita em seu texto. No contexto brasileiro parece não proceder adotar essa nova nomenclatura.
}

GUEDES-PINTO - Os mediadores das práticas de letramento... 
que co-protagonizaram suas histórias, busco apontar para determinadas posturas de trabalho com relação à formação de professores.

Durante o período de trabalho de campo, atingimos a realização de quarenta e oito (48) entrevistas, perfazendo esse total quarenta (40) mulheres e oito (8) homens. Uma de nossas tarefas na pesquisa abarcou, ao longo do projeto, a sistematização e a organização de diversas informações relativas às histórias relatadas pelos docentes. Muitas dessas informações, listadas e organizadas em tabelas ${ }^{4}$, visavam a tornar visíveis determinados aspectos constitutivos dos percursos de letramento dos professores.

Dentre os aspectos que se destacaram como constitutivos das histórias de leituras narradas pelos professores entrevistados, a diversidade de mediadores presentes no processo de apropriação da prática escrita chamou-nos atenção. Foram muitas as motivações que nos levaram a problematizar essa questão específica, destacando-se as seguintes:

a) o fato de termos ainda pouco conhecimento produzido acerca das práticas de consumo dos leitores no campo da historiografia da educação brasileira, conforme nos indica Galvão (2001). Dessa forma, estaremos ampliando o leque de informações sobre as histórias dos sujeitos leitores.

\footnotetext{
${ }^{4}$ Essas tabelas, apesar de não serem objeto de análise neste artigo, fizeram parte de uma de nossas estratégias de acesso e mergulho nas práticas de leituras narradas sobre o percurso de letramento dos professores. Foram problematizadas no relatório técnico de fevereiro de 2006 e analisadas em trabalhos apresentados nas oficinas do projeto. Elas contêm informações diversas sobre o que lêem os professores em formação e em que situações costumam ou costumavam ler. Procuramos listar essas informações tendo como referência o modo como eram mencionadas durante as entrevistas, isto é, se as leituras eram referidas pelo título apenas, pelo título seguido do autor, apenas pelo autor, ou ainda apenas sendo citado o nome da coleção de livros lida, etc.. Procuramos assim, naquele momento, tomar como base a maneira como foram ditas essas informações. Embora saibamos que, justamente pelo fato de estarmos situados em um terreno marcado por singularidades - história de leituras - que envolve, portanto, práticas plurais de letramento, acreditamos que essa organização e essa sistematização nos forneceram elementos relevantes no que se refere a como essas práticas se delineiam/delineavam e ao modo como os professores têm se apropriado dos suportes de texto (tema focalizado neste artigo). Também cremos que esse procedimento favoreceu uma aproximação das óticas dos sujeitos com quem trabalhamos nesses últimos quatro anos e meio. Sobre esse desafio de aproximação dos pesquisadores das práticas culturais pesquisadas, Chartier (2001) destaca a importância de descrevermos atentamente as inumeráveis micropráticas às quais podemos ter acesso junto aos sujeitos com os quais desenvolvemos o processo de pesquisa.
} 
b) trazer esses mediadores à tona possibilita aos pesquisadores dos Estudos do Letramento (STREET, 2007; BARTON; HAMILTON, 2000), que assumem uma perspectiva sociocultural para a compreensão das práticas de letramento, entendendo-as conforme o contexto em que se desenvolvem, acessarem informações relativas a modos singulares de apropriação da escrita;

c) a geração de conhecimento acerca desses mediadores pode subsidiar o desenvolvimento de outros letramentos que envolvam, por exemplo, a relação com tipos mais diversificados (ou mesmo inusitados) de suporte e de gênero de texto. Assim, através do acesso a essa geração de conhecimento, é possível que tenhamos a nosso alcance elementos de natureza diversa, advindos da assunção de concepções de práticas socioculturais contemporâneas, que possam contribuir para as abordagens de pesquisa e de ensino da leitura, conforme alerta Kleiman (2004) em artigo sobre as perspectivas de estudos sobre a leitura.

\section{OS ESTUDOS DO LETRAMENTO E A HISTÓRIA CULTURAL: ARTICULAÇÕES}

Conforme já mencionado, nossa pesquisa se constituiu na interface dos Estudos do Letramento com a História Cultural. A perspectiva assumida com relação aos Estudos do Letramento se pauta pelo modelo de letramento ideológico (KLEIMAN, 1995; STREET, 1984) e pelas pesquisas mais recentes produzidas principalmente por Street (2007). Nessa linha teórica a escrita é compreendida como prática social, como produto humano, marcada, portanto, pela história e pela cultura. Ao nos debruçarmos sobre as histórias de práticas de letramento que envolvem um determinado grupo profissional, como o de professores, estaremos levando em consideração os vários aspectos (culturais, sociais, históricos, profissionais, etc.) que constituem tais práticas.

Com relação à linha da História Cultural, nos pautamos na produção de Chartier $(1990,1998,2001)$, historiador francês das práticas 
da leitura, que tem focalizado os gestos e os comportamentos que as têm circunscrito e as prescrições e restrições que as têm cercado. $\mathrm{O}$ autor focaliza em seus estudos a materialidade de que se constituem os objetos que sustentam os textos, que lhe dão suporte e que também intermedeiam a relação do leitor com o texto, interferindo com isso nos sentidos atribuídos ao que é ler, ao que se lê e ao como se lê. Cavallo e Chartier (1998, p. 7) assim afirmam a respeito do perfil dessa abordagem de estudos sobre a leitura: "uma história sólida das leituras e dos leitores deve, portanto, ser a da historicidade dos modos de utilização, de compreensão e de apropriação dos textos". Ressaltam, portanto, a importância de se atentar não só para a materialidade dos textos, mas também para as práticas de apropriação desses objetos por seus leitores quando se tem intenção de investigar a história das práticas leitoras. Sobre isso ainda, Chartier (2001, p. 32-33) assevera:

As práticas são inumeráveis. Cada um de nós realiza em um dia de vida profissional ou privada milhares de práticas cotidianas, ordinárias. É impossível para a história recolher ou dar uma representação adequada dessas práticas múltiplas, porque há uma situação muito difícil para a análise. Parece-me que o que podemos fazer na história da leitura não é restituir as leituras de cada leitor do passado ou do presente, como se tratássemos de chegar à leitura do primeiro dia do mundo, mas sim, organizar modelos de leitura que correspondam a uma dada configuração histórica em uma comunidade particular de interpretação. Desta maneira, não se consegue reconstruir a leitura, mas descrever as condições compartilhadas que a definem, e a partir das quais o leitor pode produzir esta criação de sentido que sempre está presente em cada leitura.

Assim, ressalta o autor, descrever as condições em que os sujeitos foram se inserindo no mundo letrado possibilita ao pesquisador desenvolver uma forma de aproximação mais densa dos significados atribuídos à escrita por aqueles que protagonizaram uma história ou histórias como leitor e dos modos como a incorporaram em suas vidas.

É através, portanto, da articulação entre as perspectivas dos Estudos do Letramento e da História Cultural que pretendo recuperar e reconstruir, por meio das narrativas de leituras contadas pelos professores, alguns processos de apropriação da escrita tendo em vista 
suas táticas de acesso e de uso dos materiais escritos em circulação nos grupos sociais aos quais pertenciam e aos quais procuraram se integrar ao longo de seu percurso. Assim, procuro dar visibilidade às suas micropráticas de maneira que elas possam nos dar indicadores de como o processo de familiarização e inserção no mundo letrado foi se constituindo à medida que foram se tornando sujeitos leitores.

\section{AS CONTRIBUIÇÕES DA METODOLOGIA DA HISTÓRIA ORAL NA PESQUISA}

A metodologia da História Oral tem como uma de suas bases mais importantes para a pesquisa a fonte oral. Segundo Portelli $(1993,1997)$, pesquisador italiano que apresenta resultados de vários estudos sobre a história operária da Itália, dentre outros, os depoimentos orais trazem para o pesquisador diversas perspectivas de compreensão para o objeto focado, e um dos desafios da pesquisa que se colocam é trabalhar com essas várias versões. Sobre a questão de se assumir a narrativa como versão, Amado (1995) problematiza os testemunhos, destacando o quanto a modalidade oral associa, em vários níveis e de vários modos, elementos do real e da ficção, da história e da memória, da tradição e de invenção, e o quanto isso precisa ser levado em conta ao trabalharmos com as narrativas. Em nosso projeto procuramos guiar-nos por essa perspectiva, assumindo esses aspectos destacados por Portelli e por Amado como constitutivos do gênero narrativo, incorporando-os, portanto, aos limites e às possibilidades oferecidas por essa forma de assunção dos depoimentos.

Um outro ponto importante a se enfatizar a respeito da metodologia da História Oral se refere ao trabalho com a memória. Bosi (1995), psicóloga social, é uma das pesquisadoras que trouxe muitas contribuições para o âmbito dos estudos que tomam a rememoração como base, como é o caso da História Oral. A autora adverte que ao recuperarmos o passado, ao reconstruirmos nossas memórias, estamos também projetando nosso futuro e alterando nosso presente. Além disso, ressalta ela, esse processo requer mobilização de diversas naturezas do sujeito que recorda. Como diz Bosi (1995, p. 55), a memória é 
trabalho: "Na maior parte das vezes, lembrar não é reviver, mas refazer, reconstruir, repensar, com imagens e idéias de hoje, as experiências do passado. A memória não é sonho, é trabalho". Nosso grupo de pesquisa fez uso desse conceito da memória como trabalho, entendendo o processo rememorativo como um conjunto de ações que solicita momentos de esforço intelectual, que envolve vários tipos de investimento por conta do entrevistado para a consecução de seu depoimento e realização da(s) entrevista(s).

Assim, o processo rememorativo foi tomado como uma alavanca fundamental na reconstrução do percurso de letramento dos professores. Nesse aspecto, a memória de suas práticas de leitura possibilitou a ampliação da compreensão sobre a relação desse profissional do ensino com a escrita. Por meio da entrevista e da rememoração de suas trajetórias de leitura tivemos acesso às suas histórias pessoais e profissionais. Essas histórias nos possibilitaram chegar a algumas pistas para compreendermos como se deu o processo de formação do professor-leitor no decurso de sua vida pessoal e profissional e nos indicaram a existência de mediadores importantes que constituíram suas trajetórias.

Vale ressaltar também que optar por trabalhar com a abordagem da História Oral, na maior parte das vezes, significa optar pelo registro de vozes de sujeitos sociais pouco ouvidos pela sociedade mais ampla, geralmente marginalizados da vida social, silenciados pela história oficial ou mesmo desqualificados pelas instituições de prestígio e pela mídia. Acredito que a categoria social dos profissionais do ensino ainda sofre de vários estigmas, perpetuados tanto pela mídia quanto pela academia, sendo retratados, muitas vezes, como profissionais pouco ou mal qualificados para exercerem o magistério. Por essa razão, creio que nosso trabalho de pesquisa busca atuar no fortalecimento da imagem dos professores.

\section{OS MEDIADORES DAS PRÁTICAS LEITORAS}

Conforme mencionado antes, por meio do amplo conjunto de entrevistas que conseguimos realizar durante o período de 
desenvolvimento do projeto, fizemos um levantamento de informações sobre o que lêem os professores e em que circunstâncias ${ }^{5}$. Apresentamos, assim, um panorama do qual podemos inferir alguns aspectos do percurso de letramento dos professores. Chamam atenção vários mediadores presentes nesse percurso, que enumeraremos a seguir e que serão comentados ao longo deste texto.

Tais mediadores exercem funções importantes nas trajetórias relatadas. Destacam-se os papéis institucionais exercidos pela família, pelas bibliotecas públicas, pela escola, pela religião, pela lista de livros dos vestibulares das universidades renomadas, pela lista bibliográfica divulgada pelos concursos públicos e pela universidade, na mediação de práticas de leitura. Chartier e Hébrard (1995), pesquisadores franceses, realizaram um amplo projeto de pesquisa que abrangeu a recuperação dos muitos discursos que circularam sobre a leitura entre 1880 e 1980, debruçando-se na história da França desde a dominação da igreja em relação às práticas leitoras no século XIX ao empenho do estado republicano quanto à promoção da leitura em seu país. Os autores denominam "mediadores sociais da cultura" aqueles procedimentos ou aquelas instâncias que, ao responderem às políticas de divulgação da leitura, instauram medidas para formar leitores. Segundo ainda os autores, na França do final do século XX muitos desses mediadores eram chamados de animadores socioculturais. Essa observação com relação aos mediadores sociais da cultura tem relevância para o nosso estudo, pois muitos dos mediadores mencionados nos depoimentos dos professores se referem a instituições sociais ou a recursos utilizados por certas agências sociais que acabam agindo na estimulação de determinadas práticas leitoras e no estabelecimento de hierarquias ou balizamento para as leituras.

\footnotetext{
${ }^{5}$ Esse levantamento panorâmico de informações foi apresentado nas seguintes comunicações da 3a Oficina do Projeto Temático intitulada "Avanços teóricos e metodológicos", em fevereiro de 2006: "Singularidades nas práticas de leitura de professores em formação: alguns apontamentos para os estudos do letramento", de Ana Lúcia Guedes-Pinto, "Percursos de letramento: o que e como lêem os professores?", de Leila Cristina Borges da Silva, e "Momentos e lugares da leitura nas narrativas de professores em formação", de Geisa Genaro Gomes. Junto a isso, no penúltimo e no último relatórios técnicos problematizamos essas questões relativas a uma descrição minuciosa do que os professores narram sobre o que lêem e em que situações. Ver mais informações na nota de rodapé anterior.
}

GUEDES-PINTO - Os mediadores das práticas de letramento... 
Guedes-Pinto (2006, p.156), ao problematizar resultados parciais do projeto em questão e ao procurar trazer subsídios para se discutir a formação inicial dos professores e o papel da leitura nessa formação, ressaltou o quanto as bibliotecas são mencionadas nos depoimentos fornecidos pelos professores e como essa menção - freqüente - revela a importância dessas instâncias em sua trajetória de leitura. Sem elas, muitos dos sujeitos que nos relataram suas histórias provavelmente teriam sido impedidos de entrar em contato com o mundo dos livros. Afirma a autora: "[...] as professoras faziam uso da biblioteca como recurso para manter viva e em desenvolvimento sua atividade leitora".

Um outro mediador que aparece na memória de leituras exercendo um papel relevante são as listas de livros obrigatórios solicitadas pelos vestibulares das grandes universidades públicas no Estado de São Paulo, consideradas de excelência, como a Universidade de São Paulo (USP), Universidade Federal de São Carlos (UFSCAR), a Universidade Estadual de Campinas (UNICAMP), dentre outras. O efeito produzido pela publicação, divulgação e circulação social dessas listas, citado nas histórias de leitura que recolhemos, mostrou-se de forma incisiva nos relatos. Era muito comum os professores mencionarem essas listas como produtoras de um contato positivo com a prática leitora, principalmente no sentido de os porem em contato com autores literários que se tornaram marcantes em sua trajetória. Nesse aspecto, a narrativa de Fernando é exemplar:

Tinha que ler alguns livros para o vestibular, alguns livros obrigatórios e o livro que eu tenho na memória, assim, que chegou a me emocionar, que em algumas partes do livro eu cheguei a chorar mesmo, foi o livro do Manuelzão e Miguilim. Conta primeiro a história do Miguilim e depois a história do Manuelzão [...] O Guimarães Rosa, depois disso, em termos de literatura, se tornou o meu autor preferido. A minha namorada não agüenta mais, porque toda vez que ela fala assim "ah, fala o presente que você quer" no dia dos namorados, páscoa, esse tipo de coisa, eu sempre troco os meus presentes todos por livros. Ela já me deu 'Noites do Sertão', me deu 'Sagarana', me deu 'Manuelzão e Miguilim' e me deu o 'Primeiras Histórias'.

Eduardo também menciona a influência exercida por essas listas de livros. No transcurso de sua narrativa, ao comentar sobre vários livros 
lidos por ele, diz: "Li o 'Memória do Convento', que foi em noventa e nove por causa do vestibular. Muito bom, um dos melhores que eu já li’".

Acredito que as narrativas dos professores, como as citadas acima, reforçam o quanto a iniciativa das grandes universidades, ao optar por divulgar com antecipação os livros literários que irão ser abordados nas provas de português de seus exames vestibulares, trouxe como conseqüência a possibilidade de inserção de certos autores considerados clássicos ${ }^{6}$ no repertório literário dos estudantes e, em alguns casos, até despertou o gosto por essa prática sociocultural de leitura.

Outra situação bastante mencionada se refere à leitura de livros feita em função da lista de bibliografia obrigatória para os concursos públicos estaduais ou municipais para ingresso de professores nas redes de ensino. A freqüência com que apareceu esse tipo de menção aos concursos como causa ou como meio de incentivo a práticas leitoras, constitutivas do percurso de letramento, também foi alta. Esse dado reforça uma das conclusões da dissertação de Alves (2007) ao entrevistar professores da rede pública de ensino fundamental de Uberlândia, em Minas Gerais. Em seu estudo, Alves teve como objetivo recuperar a memória dos professores sobre a formação continuada oferecida pelo município mineiro. Nas narrativas dos sujeitos entrevistados apareceram de forma recorrente muitas menções às listas dos textos e dos livros obrigatórios para os concursos da rede, tornando-se assim visível seu papel como uma das agentes responsáveis por subsidiar o processo de formação continuada dos profissionais do ensino. Isto é, essas listas, de algum modo, eram entendidas como uma referência legítima que deveria ser levada em conta no encaminhamento dos estudos para as provas. E esse estudo exerceu algumas repercussões na formação docente daqueles professores. Conclui a autora (2007, p. 88):

[...] creio que os depoimentos salientam um aspecto importante na formação de professores e pouco ressaltado em pesquisas da área, que é a influência das listas de bibliografia obrigatória dos concursos públicos. Certos trechos das narrativas aqui analisadas enfatizam o quanto essas leituras foram importantes no sentido de ajudar a formar uma concepção de ensino, favorecendo

\footnotetext{
${ }^{6}$ Neste artigo não pretendo me adentrar na discussão sobre a construção de certas hierarquias de leitura e seus efeitos, principalmente na categoria dos professores dos anos iniciais do ensino fundamental. Sobre isso, ver Guedes-Pinto, 2002.
}

GUEDES-PINTO - Os mediadores das práticas de letramento... 
também a inserção desses profissionais no campo das propostas de ensino em circulação na área pedagógica.

A pesquisadora Andrade (2004), no Estado do Rio de Janeiro, justamente por reconhecer a importância das listas bibliográficas que compõem os documentos oficiais de políticas públicas para a formação de professores, escolheu como corpus de sua pesquisa os livros constantes nessas listas, sobretudo as contidas no documento de Elaboração do Currículo das Escolas Públicas do Rio de Janeiro, para estudar as práticas de leitura dos professores. Ou seja, na escolha do caminho a seguir para estudar os professores-leitores do Rio de Janeiro ela se muniu da bibliografia que constava em um dos documentos de maior circulação nas escolas públicas da cidade. Tal procedimento usado pela pesquisadora para construir seu corpus reforça os resultados encontrados em nossa pesquisa no que se refere ao importante papel das listas bibliográficas para os concursos nas práticas leitoras dos professores.

Um outro mediador social da cultura (CHARTIER; HÉBRARD, 1995) se refere às experiências religiosas. Ocorreram muitas referências a práticas religiosas de leitura ou à bíblia como único livro no domínio da vida privada. O relato abaixo nos fornece um indicativo desse panorama sociocultural:

$\mathrm{O}$ acesso que a gente teve foi bem diferente. Acho que pelo fato de a gente morar no sítio, minha mãe estudou até a terceira série, meu pai até a quarta. Então, imagine, ler, para eles, era importante, mas aquela coisa, fazia na escola. [...] O que tinha de livro em casa era a Bíblia. [...] A minha família é muito religiosa, a gente ia à igreja, a gente ia à missa.

A história da prática de leitura dos sujeitos comuns é perpassada pelo papel de regulação e interdição exercido pela igreja ao longo dos séculos no mundo ocidental, segundo informam os estudos de Chartier (1998) e de Chartier e Hébrard (1995). Silva (2004), em sua dissertação de mestrado, trabalha com essa questão da influência da religião na relação dos sujeitos com o mundo escrito. Seu trabalho mostra como as crianças, em fase inicial de apropriação da escrita, e também suas famílias, dialogam, nesse processo de inserção no mundo das letras, com suas práticas religiosas. A autora traz em seu estudo o relato de vários 
episódios vividos com sua turma de alunos, que revelam como as crianças e suas famílias interrogam os textos escritos a partir de suas experiências religiosas com a escrita bíblica, regulada e supervisionada pela igreja, seja ela católica ou evangélica. Em nossa pesquisa junto aos professores em formação inicial, a religiosidade foi, também, um aspecto importante de parte considerável das narrativas por nós analisadas.

O professor Roberto, ao apresentar sua história de leitura para a pesquisadora, construiu uma narrativa marcadamente de cunho religioso, tanto no que se refere ao conteúdo de sua trajetória de leitor, conforme segue, quanto ao modo de tecer sua história ${ }^{7}$ :

Aí eu comecei a me interessar por Deus e quis saber mais Dele. Eu comecei a ler a Bíblia. [...] Só que a Bíblia que eu tinha eu não conseguia entender, porque era tudo assim, "colocar-me-ei...", aquela linguagem arcaica, não era uma tradução fácil de entender. Eu ganhei um novo testamento assim pequenininho, não é a Bíblia toda, só um novo testamento e ele estava escrito de uma forma mais simples, que uma criança pudesse entender. E aí mudaram as histórias que eu lia. Comecei a procurar livrinho na biblioteca que falasse de Davi, Salomão, de Sansão, de Ruth, de Ester, os personagens bíblicos, Moisés. [...] Aí comecei a ler essas historinhas e eu comecei a querer ser como Jesus [...], ia para as crianças pobres da favela, doava as minhas roupas. Minha mãe ficava brava, porque eu abria aquela gaveta "ah não preciso disso, não preciso disso". Eu nunca mais deixei de fazer trabalho social, nunca mais, nenhum dia da minha vida e essa coisa começou na infância com leitura. [...] Eu começava a ler esses livros assim de superação, de desafio, de gente que conseguia ir além dos próprios limites por causa da imposição da vida. E aí a literatura minha era só essa.

\footnotetext{
${ }^{7}$ O depoimento de Roberto se apresentou para o nosso grupo como um dos mais emblemáticos, no seu conjunto, em relação ao modo de sua narração. Trata-se de um relato que se assemelha, em muito, à história de Jesus Cristo. Há diversos elementos que fazem parte da tessitura de sua narrativa que fazem referência aos episódios vividos por Jesus. O relato de Roberto já foi objeto de análise de nossa equipe por duas vezes, nas seguintes comunicações: "Professoras leitoras em formação: como narram suas práticas", de Leila Cristina Borges da Silva, no $4^{\circ}$ Seminário Letramento do Professor: resultados e perspectivas, em julho de 2007, e "Veracidade e imaginação na história de leitura de professores: diálogos com o 'grande mentiroso"', de Ana Lúcia GuedesPinto, no IX Encontro Nacional de História Oral em abril de 2008.
}

GUEDES-PINTO - Os mediadores das práticas de letramento... 
O relato de Roberto contém tanto informações específicas sobre o que lia e sobre suas leituras religiosas, como também sobre seu próprio estilo de construir sua narrativa, de relatar os episódios, que estão misturados pela forma de narrar bíblica, aparecendo diversos elementos em sua história que lembram a vida de Jesus Cristo, remetendo-nos ao texto bíblico. Roberto narra sua trajetória de leitura como uma história de superação, durante a qual experimentou quarenta dias de sofrimento em que passou fome, frio e abandono, privações terríveis, que superou, entre outros motivos, graças ao que encontrou nos livros. Na realidade, percebemos em sua construção narrativa características da intertextualidade em sentido restrito $\left(\right.$ Koch, 1998) ${ }^{8}$, em que é revelada a intersecção de elementos presentes na narrativa bíblica atribuída à peregrinação de Jesus Cristo e da história pessoal que Roberto nos conta. Assim, tornam-se visíveis aspectos de sua imaginação e da cultura religiosa que se enredam no relato de sua própria história de vida, semelhante ao que Amado (1995, p.16) identifica em seu texto sobre o informante Fernandes, denominado em seu artigo como o grande mentiroso. A autora afirma sobre essa questão da simbologia contida em cada narrativa:

Inerente às entrevistas, existe, entretanto, uma dimensão simbólica, que os historiadores têm a obrigação de conhecer e estudar, pois, faz parte da história. Mediadas pela memória muitas entrevistas transmitem e reelaboram vivências individuais e coletivas dos informantes com práticas sociais de outras épocas e grupos. A dimensão simbólica das entrevistas não lança luz diretamente sobre os fatos, mas permite aos historiadores rastrear as trajetórias inconscientes das lembranças e associações de lembranças; permite, portanto compreender os diversos significados que os indivíduos atribuem às experiências que têm.

${ }^{8}$ Koch (1998), baseada nos autores alemães Beaugrande e Dressler, ao abordar a questão da construção dos sentidos no texto, refere-se à intertextualidade como um elemento constitutivo da textualidade, isto é, como uma das características inerentes de um texto. A autora apresenta uma distinção entre intertextualidade em sentido amplo e em sentido restrito. No caso da narrativa de Roberto, observamos que a intertextualidade se configura em sentido restrito, pois ela se estabelece entre textos efetivamente existentes, já produzidos, como é o caso do texto bíblico. Ainda na situação analisada, a intertextualidade é tanto explícita, quando o narrador faz referência direta às histórias da bíblia, como também é de forma/conteúdo, pelo fato de identificarmos um estilo narrativo que se assemelha ao estilo narrativo bíblico, indiciando uma tentativa de reprodução desse discurso. 
Amado (1995) traz para a problemática da análise do historiador oral a importância de se levar em conta a tessitura dos eventos narrados, as várias nuanças que constituem a narrativa. Tomando a perspectiva das ciências da linguagem tal qual assumida por Bakhtin (1997), podemos dizer que a polifonia faz parte das narrativas dos professors, sendo constitutiva de seus discursos. Identificamos variadas vozes presentes em suas histórias - as vozes do discurso escolar, as vozes da universidade, as vozes da família, as vozes da religião - tornando, assim, visível como os processos de apropriação da cultura escrita dialogam com diferentes instâncias sociais que também têm diferentes poderes na circulação dos discursos. Sobre isso, Guedes-Pinto, Gomes e Silva (2005), ao se deterem na análise de resultados parciais da pesquisa em questão, baseadas também nos estudos de Bakhtin, salientam a presença dos diversos discursos (não necessariamente convergentes) que convivem nos dizeres dos professores sobre suas práticas leitoras.

A família, igualmente, é citada como um relevante mediador sociocultural da leitura, seja pelo papel da oralidade entre seus integrantes no cotidiano da vida doméstica como ponte ou apoio para a apropriação do escrito quando havia carência de materiais escritos, seja como exemplo de postura a se ter na escola ou a se ter como futuro leitor. Nesse aspecto, a professora Elisa chama atenção a respeito da importância da formação dada pelos pais: " $E$ eu fiquei pensando sobre o fato de ter todos esses livros em casa e de sempre ter visto os meus pais lerem".

Os mediadores pessoais, isto é, os sujeitos com os quais se depararam em seu percurso, como os irmãos, algum professor da escola em particular, amigos, patrão ou patroa, amigo fazendeiro que tinha uma biblioteca em casa, etc., também exerceram funções importantes nas trajetórias dos professores. O professor em formação Osmar comenta como foi importante a influência que recebeu de seu companheiro de república para afirmar-se como sujeito-leitor:

Eu moro com um rapaz que faz doutorado. Ele faz doutorado em Lingüística. Ele fez jornalismo. [...] Eu comecei a ter um hábito melhor de leitura por causa dele, porque eu divido o quarto com ele e ele lia muito. Eu comecei a ler mais por causa dele, porque eu via o cara lendo [...] e eu comecei a ler. [...] Então eu comecei a ler um livro quando comecei a dividir o quarto com 
ele, 'Anarquistas Graças a Deus', da Zélia Gattai, que eu tinha em casa. Eu quis ler aquele livro. E agora eu estou lendo [...] 'Pedagogia Popular' do Freinet e estou gostando bastante. Eu comecei a pegar coisa que estava me interessando e que tem a ver com as minhas convicções políticas, tem a ver um pouco com aquilo que eu penso. E eu converso muito com ele [sobre as leituras].

Pompougnac (1997, p. 46), estudioso das práticas de leitura na França, menciona o papel do outro na constituição do leitor que vai ao encontro do que foi citado pelo professor Osmar: "O papel do par não é apenas levar a descobrir ou dar novos textos para ler. Testemunho das novas leituras, ele ajuda a consegui-las e a 'certificar' o novo leitor".

Creio que todos os excertos anteriormente analisados nos remetem à nossa responsabilidade, como pesquisadores, de nos aproximarmos da ótica dos sujeitos pesquisados de modo a compreender suas práticas de leitura. Barton e Hamilton (2000, p. 13), com relação aos Estudos do Letramento, destacam que, quando estamos diante de práticas culturais, como é o caso das práticas sociais em que há a escrita, não devemos esquecer que essas mesmas práticas têm seus alicerces fundados em um passado. E acessar esse passado, isto é, retomar na história a gênese de tais práticas, possibilita ao pesquisador perceber quais aspectos ideológicos, da tradição e da cultura podem estar nelas envolvidos. Assim, tomando como referência o conceito de letramento situado, utilizado pelos autores, podemos assumir e entender essas práticas que envolvem a escrita através da ótica de sua inserção no movimento da história social, levando-se em conta as disputas e lutas de força que compõem a história das práticas de letramento.

Um último aspecto que pretendo focar como item deste texto se volta ao papel desempenhado pela universidade na formação dos professores.

Nas falas dos estudantes, professores em formação, a referência à experiência universitária surgiu também com freqüência, trazendo força para esse espaço e esse tempo específicos em que nossa intervenção como professores universitários acontece de uma forma direta, visto que atuamos cotidianamente nos cursos de formação de professores, de cujo quadro docente fazemos parte. 
Elisa é uma das professoras que comenta a respeito da influência da universidade:

Eu vou comprando livros que falam para mim, que me indicam. Anoto tudo, principalmente o que as professoras [da faculdade] falam na sala de aula, eu vou anotando tudo no meu caderno. Vou lá ao sebo. O que eu acho eu compro, guardo, nas férias eu leio, sabe? Então eu leio assim, tenho um gosto bem eclético, vários tipos de leitura, gosto dos romances, gosto de romance histórico, gosto dos livros que eu li aqui [na faculdade].

A professora Joana destaca em seu dizer o tempo que dedica às leituras do curso de Pedagogia: "Leio tudo da faculdade. Faço questão. Procuro não deixar o texto, assim, de ler só o comecinho, sabe, por alto. Leio tudo da faculdade, faço muita pesquisa lá onde eu trabalho, porque eu preciso ler bastante pra dialogar com as professoras, né?”.

Por outro lado, acessamos uma perspectiva diferente a partir da narrativa de outra estudante. Júlia não se refere com satisfação às práticas leitoras vividas na faculdade:

Aqui [referindo-se ao curso de Pedagogia], honestamente, já não foi um lugar de tanto incentivo à leitura apesar de tudo. Tinham os textos, mas era aquela leitura mais obrigatória. Tinha que ler para a aula, mas eu acho até que eu perdi um pouco daí essa coisa de ler o que eu gostava de ler por ler. É uma coisa que só fica nas férias agora, né, porque não tem tempo hábil, você tem as obrigações da leitura.

Os excertos acima tornam visível a importância que a nossa mediação, como professores de cursos universitários que formam futuros professores, tem na formação de práticas de leitura daqueles que já formaram - os professores que já exercem a profissão docente na escola básica - e daqueles que irão formar outros leitores - os futuros professores, que apenas cursam a graduação sem atuar, no entanto, no ensino. Tais excertos também nos mostram que nossos estudantes não apresentam de forma alguma características que apontem para um grupo social homogêneo que, portanto, seria afetado a partir de uma ou de algumas maneiras de ensinar. Esses excertos nos informam o quanto o percurso dos professores em formação difere na maior parte das vezes e o quanto nossas formas de abordagem em relação à leitura em nossas 
salas de aula solicitam de nós um amplo repertório em relação à compreensão do que seja ler. Talvez, mais do que necessitar de um amplo repertório, essas diferentes trajetórias nos mostrem o quanto precisamos ser abertos e receptivos para uma pluralidade de manifestações culturais. De Certeau (1995) já alertava a respeito dessa diversidade social que se apresentava no final dos anos 60 e na década de 70 do século XX na realidade dos bancos universitários franceses.

\section{CONSIDERAÇÕES FINAIS}

Os diversos depoimentos com os quais nos defrontamos no período de realização da pesquisa nos fazem ver a singularidade dos percursos e as diferentes maneiras de apropriação e de significação da cultura escrita pelos sujeitos. Chartier (2001, p. 116-117) salienta que essas diferenças nos modos de inserção no mundo escrito se relacionam com as forças desiguais existentes entre as comunidades de leitores. Ele nos alerta:

É preciso situar as apropriações dentro das relações sociais que definem um mundo social particular e, ao mesmo tempo, talvez deva-se retomar algo do sentido foucaultiano deste termo, que assinala que há sempre uma vontade de monopólio, de controle, de propriedade, e que a apropriação não se dá por si mesma, mas como resultado de um conflito, de uma luta, de uma vontade em confronto com outra.

Assim, ao trabalharmos com nossos estudantes nos cursos de formação de professores, é importante levarmos em conta que essa "vontade de monopólio" faz parte do mundo elitista universitário brasileiro, constituindo, portanto, as práticas socioculturais universitárias, e por essa razão necessariamente nos defrontaremos com elas em nossas práticas formativas.

Todas essas advertências e cuidados que nosso trabalho de pesquisa aponta em relação à apreensão e à compreensão do percurso de letramento dos professores potencializam nossas possíveis intervenções e nosso papel social como formadores de futuros professores. Se, com o desenvolvimento de nosso projeto de pesquisa, encontramos resultados 
que re-afirmam a constatação de uma pluralidade das práticas de leitura e que nos indicam que temos tido contato, ao longo do tempo histórico vivido na universidade, com leitores plurais, isso significa que precisamos encontrar, por nosso lado, modos plurais de ação pedagógica junto a esses profissionais que historicamente têm sido formados por nós.

\section{REFERÊNCIAS}

ALVES, M. C. S. O. A formação continuada na rede municipal de ensino de Uberlândia (1990-1995): com a palavra os professores. Dissertação (Mestrado em Educação) - Faculdade de Educação, Unicamp, Campinas, 2007.

AMADO, J. B. O Grande Mentiroso: tradição, veracidade e imaginação em história oral. História, São Paulo, v. 14, p. 125-136, 1995.

ANDRADE, L. T. Professores-leitores e sua formação: transformações discursivas de conhecimentos e de saberes. Belo Horizonte: Ceale; Autêntica, 2004.

BAKHTIN, M. Estética da criação verbal. 2. ed. São Paulo: Martins Fontes, 1997.

BARTON, D.; HAMILTON, M. Literacy practices. In: BARTON, D.; HAMILTON, M.; IVANIC, R. Situated literacies: reading and writing in context. London: Routledge, 2000.

BOSI, E Memória e sociedade: lembranças de velhos. 3. ed. São Paulo: Companhia das Letras, 1995.

CAVALLO, G.; CHARTIER, R. Introdução. In: CAVALLO, G.; CHARTIER, R. (Orgs.). História da leitura no mundo occidental - 1. São Paulo: Ática, 1998.

CHARTIER, A.-M.; HÉBRARD, J. Discursos sobre a leitura - 1880-1980. São Paulo: Ática, 1995.

CHARTIER, R A história cultural: entre práticas e representações. Lisboa, Portugal: Difel, 1990.

A aventura do livro: do leitor ao navegador. São Paulo: Unesp, 1998.

Cultura escrita, literatura e história. Porto Alegre: ARTMED, 2001. 
DE CERTEAU, M. A cultura no plural. Campinas: Papirus, 1995.

GALVÃO, A. M. O. Leituras de professores e professoras: o que diz a historiografia da educação brasileira. In: MARINHO, M. (Org.). Ler e navegar: espaços e percursos da leitura. Campinas: Mercado de Letras; Associação de Leitura do Brasil, 2001.

GUEDES-PINTO, A. L. Rememorando trajetórias da professoraalfabetizadora: a leitura como prática constitutiva de sua identidade e formação profissionais. Campinas: Mercado de Letras; São Paulo: Fapesp, 2002.

Percursos de letramento em narrativas de professores: subsídios para a reflexão sobre a formação inicial. Horizontes, v. 24, n. 2, 2006.

GUEDES-PINTO, A. L.; GOMES, G. G.; SILVA, L. C. B. Percursos de letramento dos professores: narrativas em foco. In: KLEIMAN, A. B.; MATENCIO, M. L. M. (Orgs.). Letramento e formação do professor: práticas discursivas, representações e construção do saber. Campinas: Mercado de Letras, 2005.

KLEIMAN, A. B. Modelos de letramento e as práticas de alfabetização na escola. In: KLEIMAN, A. B. (Org.). Os significados do letramento: uma perspectiva sobre a prática social da escrita. Campinas: Mercado de Letras, 1995.

Abordagens da leitura. Scripta, v. 7, n. 14, 2004.

KOCH, I. V. O texto e a construção dos sentidos. 2. ed. São Paulo: Contexto, 1998.

POMPOUGNAC. Relatos de aprendizado. In: FRAISSE, E.; POMPOUGNAC, J.-C.; POULAIN, M. Representações e imagens da leitura. São Paulo: Ática, 1997.

PORTELLI, A. Sonhos ucrônicos: memórias e possíveis mundos dos trabalhadores. Projeto História, São Paulo: EDUC, n. 10, abril, 1993.

. Tentando aprender um pouquinho: algumas reflexões sobre a ética na história oral. Projeto História, São Paulo: Abril, n. 15, 1997.

SILVA, L. C. B.. Práticas de leitura na infância: do limite à transgressão. Dissertação (Mestrado em Educação) - Faculdade de Educação, Unicamp, Campinas, 2004.

STREET, B. V. Literacy in theory and practice. Cambridge: Cambridge University Press, 1984. 
New literacies, new times: how do we describe and teach the forms of literacy knowledge, skills and values people need for new times? 2007. (mimeo)

Recebido em 16/08/08. Aprovado em 23/09/08.

Title: Mediators of teachers-in-training literacy practices

Author: Ana Lúcia Guedes-Pinto

Abstract: In this article we analyse data produced by the research project "Teachers' Education: the process of reading and literacy practices", focusing on the appropriation of reading practices experienced by teachers in training in their initial courses. From the narratives of their memories of personal experiences from childhood, adolescence, and current times in college, we were able to identify how they acquired literacy practices during their lives. In the process of entering the world of writing reported by the teachers in training, several mediators of their reading practices emerged. Adopting the theoretical and methodological framework of Oral History, the principles of ethnography, the New Literacy Studies and the Cultural History approach, we identify these different mediators and discuss their roles in the teachers' in training educational history. On the basis of their narratives of past readings and on what they reveal about several characters that are part of their history, we indicate possibilities of teaching practices for the training of new teachers.

Keywords: literacy; reading; teacher education; memory; narrative.

Titre: Les médiateurs des pratiques de littératie de professeurs dans la formation initiale

Auteur: Ana Lúcia Guedes-Pinto

Résumé: Prenant comme base la génération de données acquises par la recherche "Formation du professeur: procès de retextualisation et pratiques de littératie", je focalise le procès d'appropriation de la pratique de lecture vécue par les professeurs en formation initiale. Dans leurs narrations de mémoire sur leurs expériences personnelles de l'enfance, de la jeunesse et de la contemporanéité du cours de Pédagogie, nous avons identifié des indices de comment ces sujets se sont insérés dans les pratiques de littératie desquelles ils s'approprient tout au long de leurs parcours. Dans ce procès d'insertion dans le monde de l'écriture, selon ce qu'ils ont dit, plusieurs médiateurs émergent de leurs pratiques de lectures. Ayant comme référence théricométhodologique du travil de champ, l'Histoire Orale, les principes de l'ethnographie et assumant l'abordage des Études de la Littératie et de l'Histoire Culturelle, je cherche à identifier ces différents médiateurs et discuter leur rôle dans le parcours de lectures narrées et ce qu'elles nous apportent de connaissance sur des personnages divers qui jouent leurs histoires en même temps, je cherche à désigner des possibilités de travail en rapport à la formation de professeurs.

Mots-clés: littératie; lecture, formation de professeurs; mémoire; narration.

GUEDES-PINTO - Os mediadores das práticas de letramento... 
Título: Los mediadores de las prácticas de literacia de profesores en formación inicial Autor: Ana Lúcia Guedes-Pinto

Resumen: Tomando como base la generación de datos proporcionada por la investigación "Formación del profesor: procesos de retextualización y prácticas de literacia", focalizo el proceso de apropiación de la práctica de lectura vivenciado por los profesores en formación inicial. En sus narrativas de memorias sobre sus experiencias personales de la infancia, de la juventud y de la contemporaneidad del curso de Pedagogía, identificamos indicios de como esos sujetos se insertaron en las prácticas de literacia de las cuales se apropiaron a lo largo de sus recorridos. En ese proceso de inserción en el mundo de la escrita, conforme narrado por los profesores, emergen diversos mediadores de sus prácticas lectoras. Teniendo como referencia teóricometodológica del trabajo de campo la Historia Oral, los principios de la etnografía y asumiendo el abordaje de los Estudios de la Literacia y de la Historia Cultural, busco identificar esos diferentes mediadores y discutir su papel en el recorrido de formación del profesional de la enseñanza. Considerando, por lo tanto, las memorias de lecturas narradas y lo que ellas nos traen de conocimiento acerca de los variados personajes que coprotagonizaron sus historias, busco apuntar posibilidades de trabajo en relación a la formación de profesores.

Palabras-clave: literacia; lectura; formación de profesores; memoria; narrativa. 